\title{
NIÑOS EN AUSCHWITZ: UNA REFLEXIÓN FILOSÓFICO-PEDAGÓGICA
}

Children in Auschwitz: A philosophic-educational contemplation. Crianças em Auschwitz: Uma reflexao filosófica-pedagógica

\section{Jaime Montes Miranda}

Universidad de La Serena, Chile. Fono: +5699552091. Correo electrónico: jmontes@userena.cl

\section{Resumen}

Nos preguntamos por la dimensión filosófica y pedagógica de Auschwitz. Pero esto no es posible sin hacer previamente la experiencia de Auschwitz. Para contar esa experiencia nos servimos de dos testimonios excepcionales: Imre Kertész y Primo Levi. El primero ingresó a Auschwitz siendo todavía un niño, con apenas quince años de edad. El segundo, en plena juventud, descubre como nadie la esencia profunda de Auschwitz. Ambos serán nuestros guías por los senderos del infierno. En un segundo momento atenderemos a esa dimensión simbólica de Auschwitz. Por esa dimensión, Auschwitz encarna la muerte de lo humano del hombre en el mundo. Con la palabra Auschwitz designamos ese gesto que propicia y consuma la muerte de lo humano del hombre en el mundo. Nosotros, desde la educación pensamos en la dimensión simbólica de Auschwitz. No es necesario estar recluido en un campo de exterminio para asistir a la muerte de lo humano del hombre. Nuestra sociedad está siempre rozando la frontera que distingue lo humano y lo inhumano. La extrema violencia, dentro y fuera de los recintos educativos manifiesta que Auschwitz está siempre a la vuelta de la esquina. La muerte de lo humano del hombre en la sociedad en que vivimos es una tentación demasiado seductora como para renunciar a ella. Por nuestra parte, pensamos que teniendo en Auschwitz un referente valórico esencial es posible aprender a optar por una respuesta más constructiva y edificante. En ese gesto, esencialmente compasivo, encontramos los fundamentos para la construcción de un nuevo humanismo.

Palabras claves: Auschwitz, Humanismo, Educación, Infancia, Memoria

\section{Abstract}


We asked ourselves about the philosophical and pedagogical dimension of Auschwitz. But this is not possible unless we first make the experience of Auschwitz. In order to get that experience we can use two exceptional testimonials: Imre Kertész and Primo Levi. The first one entered Auschwitz still a child, with only fifteen years old. The second, in his youth, discovers the profound essence of Auschwitz as no one else. They will drive us along the paths of hell. Afterwards, we will approach the symbolic dimension of Auschwitz, in which, Auschwitz embodies the death of humanism in men. By spelling the word Auschwitz we mean what promotes and destroys the humanism of world mankind. From the point of view of education we use to think about the symbolic dimension of Auschwitz. It is not necessary to be confined in an extermination camp in order to watch the death of humanism between men. Our society is always slipping in the border which separates the human from not human. The extreme violence in and out the educational precincts, is telling us that Auschwitz is always just around the corner. The death of humanism in our society is a temptation too exciting to give it up. By having Auschwitz as a crucial example - in our view - it is possible to choose a more constructive and inspiring response. In that merciful context, we can always find the foundations for the construction of a new humanism.

Key words: Auschwitz, Humanism, Education, Childhood, Memory

\section{Resumo}

Neste trabalho nos perguntamos sobre a dimensão filosófica e pedagógica de Auschwitz. Mas isso não é possível sem primeiro fazer a experiência de Auschwitz, para o qual usamos dois testemunhos excepcionais: o de Primo Levi e de Imre Kertesz. O primeiro entrou em Auschwitz sendo criança, com apenas 15 anos de idade. O segundo descobriu como ninguém, na sua juventude, o que significa a profunda essência de Auschwitz. Ambos serão nossos guias ao longo dos caminhos do inferno. Num segundo momento analisaremos a esta dimensão simbólica de Auschwitz. Dimensão que encarna no caso de Auschwitz a morte da humanidade do homem no mundo. Com a palavra Auschwitz se designa o gesto que promove a morte e consome a humanidade do homem no mundo. Nós, precisamente, refletimos sobre esta dimensão simbólica de Auschwitz desde a educação. Não há 
necessidade de ser confinado em um campo de extermínio para assistir à morte da humanidade do homem. Nossa sociedade está sempre perto da fronteira que distingue o humano do inumano. A extrema violência, dentro e fora dos estabelecimentos educativos, manifesta que Auschwitz está sempre ao virar da esquina. A morte do humano do homem na sociedade em que vivemos é uma tentação muito atraente para deixar passar. De nossa parte, pensamos que ter uma referência essencial baseada no valor Auschwitz, permite aprender a optar por uma resposta mais construtiva e edificante. Nesse gesto, essencialmente compassivo, achamos as bases para a construção de um novo humanismo.

Key words: Auschwitz, Humanismo, Educação, Crianças, Memória

« ¡Pobre flor! ¿Qué mal naciste! ¿Qué fatal que fue tu suerte! Al primer paso que diste tropezaste con la muerte....» Miguel Hernández.

\section{Visitas y aprendizajes}

Visité hace algunos años, con ocasión de un congreso, los campos de exterminio nazis de Auschwitz I y Auschwitz II - Birkenau, situados en las afueras de la hermosa Cracovia, en Polonia. El recorrido del recinto se iniciaba con la visita al Museo Estatal AuschwitzBirkenau, donde se podía apreciar mediante la exhibición de diversos documentos y testimonios la magnitud del genocidio perpetrado en esas instalaciones, durante la II Guerra Mundial. Después de la visita quedaba cada cual en libertad para recorrer el lugar, cosa que preferí hacer a solas y en silencio. Costó dar los primeros pasos. Finalmente elegí un sendero y caminé. Seguramente seguí el mismo derrotero que hicieron infinidad de veces los prisioneros, rumbo a los trabajos forzados o hacia las cámaras de gas. Apenas podía imaginarme la hilera de aquellos hombres con el famoso uniforme de rayas marchando hacia los campos de trabajo, con paso tembloroso y dolorido. Allí estaban, a la vista del turista, las barracas, los hornos crematorios, las vías del tren penetrando Birkenau y tantos otros monumentos análogos. Pero el horror mismo que debió ser ‘eso’ no estaba. Por lo pronto, renunciamos a imaginar lo que debió ser 'aquello' para las miles y miles de personas que presenciaron horrorizadas la muda muerte sin siquiera saber el porqué de su sacrificio. Entre ellos, miles y miles de niños. El cine y la literatura nos han permitido 
hacernos una idea del horror, a sabiendas que siempre habrá una distancia insalvable entre la percepción desde las butacas y la gris realidad tras las alambradas.

Por hablar sólo de cine, tal vez la película que más impresionó sobre el tema "Auschwitz" a las primeras generaciones fue El diario de Ana Frank cuya primera versión data de 1959. Aunque nunca se muestra ningún campo de exterminio ni nada relacionado directamente con ellos, sin embargo, se siente la opresión de toda una ciudad sobre esas familias arrinconadas en una buhardilla durante años procurando escapar de la barbarie nazi. El film alcanzó una notoriedad sobresaliente. Sin embargo, es en nuestros tiempos cuando la infancia adopta un rol central en el cine concentracionario. Spielberg nos estremeció con su film, El imperio del Sol (1987) en el que un niño inglés perdido en la ciudad china de Shanghái, Jamie 'Jim' Graham, termina codeándose con la barbarie en un campo de concentración japonés. Es conmovedora la escena en la que le espeta a su amigo Basie: "Me enseñaste a que la gente es capaz de todo por una patata". Del mismo Spielberg también recuerdo con emoción la niñita del abrigo rojo que aparece en La lista de Shindler (1993) durante la evacuación del gueto de Cracovia. La vemos viva, asustada, caminando entre la locura desatada, y al cabo de unos instantes solo vemos sus restos incinerados. De más actualidad es todavía El niño con el pijama de rayas (2008) en donde un par de niñitos terminan gaseados y destruidos. En todos estos casos, gracias a la magia del cine, podemos aproximarnos a la vida de estos personajes condenados a temprana edad al infierno y la muerte.

Resulta particularmente dolorosa la escena que nos cuenta Levi de una jovencita en Auschwitz, sobreviviente de la cámara de gas ${ }^{1}$. Expresa el horror en su grado máximo:

En la cámara de gas acababan de ser amontonados y asesinados los integrantes de un convoy que acababa de llegar, y la Escuadra estaba llevando a cabo su horrendo trabajo cotidiano de desenredar la maraña de cadáveres, lavarlos con mangueras y transportarlos al crematorio, pero en el suelo se encontraron con una joven que aún vivía. Era un acontecimiento excepcional, único; tal vez los cuerpos hayan formado una barrera a su alrededor, hayan capturado un saco de aire que conservó el oxígeno. Los hombres estaban perplejos, la muerte era su trabajo cotidiano, la muerte era una

\footnotetext{
${ }^{1}$ Se hizo una película llamada en español, La zona gris (2001). Con algunas libertades, refiere esencialmente esta narración de Levi.
} 
costumbre, porque precisamente 'o se enloquece uno el primer día o se acostumbra', pero aquella mujer estaba viva. La esconden, la calientan, le llevan caldo de carne, la interrogan: la chica tiene dieciséis años, no puede orientarse ni en el espacio ni en el tiempo, no sabe dónde está, ha recorrido sin entender nada la hilera del tren sellado, la brutal selección preliminar, la expoliación, la entrada en la cámara de donde nadie ha salido nunca vivo. No ha entendido nada, pero lo ha visto; por eso debe morir, y los hombres de la Escuadra lo saben, como saben que ellos morirán por la misma razón. Pero estos esclavos embrutecidos por el alcohol y por la matanza cotidiana se han transformado; delante de sí no tiene ya a una masa anónima, el río de gente espantada, atónita, que baja de los vagones: lo que hay es una persona. (Levi, 2002b: 69-70).

Levi nos cuenta como esos hombres endurecidos y embrutecidos son capaces de realizar el gesto ético esencial, a sabiendas que ella tiene sus minutos contados. La cuidan, la protegen, la alimentan. Se confabulan para mantenerla oculta a pesar de la inutilidad del gesto. Visos de humanidad destellan en las mentes de esos prisioneros condenados a ejecutar el genocidio y a morir luego. Pero el fin no tarda en llegar:

Se llamó a un médico, quien reanimó a la chica con una inyección: sí, el gas no ha cumplido su cometido, podrá sobrevivir, pero ¿dónde y cómo? En aquel momento llegó Muhsfeld, uno de los militantes de la SS adscrito a las fábricas mortales; el médico lo llama aparte y le explica el caso; Muhsfeld duda, luego decide: la chica tiene que morir. Si fuese mayor el caso sería distinto, ella tendría una actitud más madura y tal vez se la podría convencer de que callase todo lo que le había sucedido, pero tiene sólo dieciséis años: no podemos fiarnos de ella. No la mata con sus propias manos, llama a un subordinado suyo para que la mate de un golpe en la nuca. (Levi, 2002b: 71-72).

Una película significativa aunque tal vez no muy conocida lleva entre nosotros por título Sin destino. El nombre original en húngaro es Sorstalanság, traducido al español como Campo de esperanza (2005). Está inspirada sobre una novela autobiográfica ${ }^{2} \mathrm{de}_{\mathrm{Imre}}$ Kertész, sobreviviente del Holocausto nazi y Premio Nobel de Literatura (2002), llamada también Sin destino (1975).

\footnotetext{
${ }^{2}$ Kertész ha tenido problemas para encasillar su escrito, pues para él novela y autobiografía son géneros distintos e incompatibles aunque sus criterios son más bien literarios, dado que termina asumiendo que las vivencias de su personaje György fueron también las suyas propias. Por ello, en adelante nosotros también asumiremos el carácter autobiográfico de su novela, aunque haya ficción en algunos contextos por exigencias literarias, y en muchos casos nos referiremos a Kertész cada vez que hagamos alusión a las experiencias de György.
} 
Imre Kertész ingresó a Auschwitz a la edad de quince años. Esto por sí mismo significa muchas cosas difíciles de comprender. La sola presencia de Kertész en Auschwitz contando con apenas quince años de edad debe llenarnos de desazón y amargura. Un niño en Auschwitz. ¿Qué hace un niño en Auschwitz? Recuerdo aquella estremecedora fotografía de un niño, muy menor, con la estrella amarilla en el pecho y con las manos arriba en el gueto de Varsovia y siento algo parecido. Náuseas ante lo incomprensible. Hay muchas fotos que testimonian la presencia de niños en Auschwitz. ¿Qué hace un niño en Auschwitz? Y no podemos dejar de hacernos muchas preguntas a pesar de que probablemente ninguna tenga respuesta. Cualquier comprensión requiere lenguaje, y 'eso' que encarna Auschwitz está más allá del lenguaje. Auschwitz nos enseña una experiencia esencial: que el mal en su radicalidad extrema apenas se puede decir, pero que a pesar de ello, genera emociones y plantea problemas a la inteligencia. Hoy Auschwitz es un recinto de silencio, recogimiento y enseñanzas. La UNESCO lo declaró Patrimonio de la Humanidad en 1979. Auschwitz es de todos. Visitado por estudiantes de todo el mundo, acudir a Auschwitz es, en sí mismo, una lección de humanidad; el campo enseña su propia filosofía. El Auschwitz del que hablamos no es un recinto turístico. Allí se va a recordar y a imaginar lo acontecido y sobre todo a pensar si es que aún dispondremos de un futuro humano en este siglo que recién comienza, es decir, un futuro digno de ser vivido o, por el contrario, volverá a reinar la barbarie. Y esa meditación, obviamente, se hace a solas y en silencio.

\section{Auschwitz y el fin de lo humano.}

Nosotros seguiremos de cerca las experiencias de Kertész y Levi, tal como éstas quedaron consignadas en sus obras más emblemáticas: Sin destino, escrita por Kertész en 1975 y Si esto es un hombre, escrita por Levi en 1958.

No realizaremos un análisis exhaustivo o 'científico' de estas obras. Sólo rescataremos algunos textos que expresen del modo más diáfano posible la experiencia de la muerte de lo humano del hombre en el mundo, que es en el fondo la esencia profunda de Auschwitz. 
Auschwitz es el camino progresivo que conduce desde la condición de persona a la condición de cosa y finalmente a nada más que humo, "de aquí sólo se sale por la chimenea" escuchaba a menudo Levi en Auschwitz. Ese es el misterio de Auschwitz.

En Auschwitz, suele decir Elie Wiesel, no murió sólo el judío sino también el hombre. La humanidad del hombre, esos triunfos parciales logrados por el ser humano sobre la barbarie a lo largo de los siglos, quedó pulverizada, en algunas de sus zonas vitales, en las cámaras de gas. Y, en primer lugar, la capacidad de memoria. Hay que tener en cuenta, en efecto, que Auschwitz no fue sólo una gigantesca fábrica de muerte sino también un proyecto de olvido. Todo estaba pensado para que no quedara ni rastro, por eso todos tenían que morir y los cadáveres debían ser quemados, los huesos molidos y luego aventados. Lo más singular de este acontecimiento es, como dice el historiador francés Vidal Naquet, "la negación del crimen dentro del crimen" para que no hubiera huella en la memoria de la humanidad. (Reyes, 2003: 9).

El misterio de Auschwitz refiere especialmente a su incomprensibilidad, a la dificultad de poder reducirlo dentro de un esquema racional. De hecho no tenemos una palabra en nuestro idioma para designar "eso" que llamamos Auschwitz. Auschwitz señala un campo en especial con una situación geográfica precisa. Pero hubo muchos otros campos de exterminio de la Alemania nazi. Y otros tantos desde entonces en todo el mundo. Y no olvidemos nuestra Villa Grimaldi, por referirme al más emblemático de los Lager chilenos. La palabra Holocausto que se ha empleado a veces tampoco es exacta, ni la palabra Shoah. Y no es que no sepamos lo que allí sucedió. La información está completa. Sin embargo, Auschwitz sigue siendo un desafío para nuestra inteligencia.

Por otra parte, nuestro camino avanza en sentido contrario al impuesto por Auschwitz. Deseamos transitar desde esa condición de nada y cosa hacia la condición de persona, optamos por la humanidad. Si Auschwitz es el camino hacia la nada, el nuestro será un camino hacia el sentido. Pero ese sentido no puede construirse de espaldas a Auschwitz. Como si Auschwitz jamás hubiera ocurrido.

Por ello siempre tenemos a la vista, en el pensamiento, la muerte de lo humano del hombre en el mundo. Ese sigue siendo nuestro tema principal. "La muerte de lo humano del hombre ha sido la gran herencia del siglo que acaba de consumirse. Por lo mismo, pensar a 
la altura de esa experiencia de la muerte de lo humano en el hombre constituye el desafío de nuestro tiempo". (Montes, 2014:79).

La muerte de lo humano del hombre en el mundo se da de mil maneras. No es sólo una experiencia histórica que se haya dado en un lugar y momento. La muerte de lo humano está permanentemente presente en la vida y también, por supuesto, en la educación. Se trata de una cuestión propia de la ética filosófica y de la ética pedagógica. Tiene que ver con gestos y valores. Con gestos cargados de valor, gestos que reivindican el valor absoluto de la persona humana o por el contrario, gestos que la niegan y destruyen. Es una opción para el hombre de hoy: hacer que prevalezca el gesto ético o hacer que prevalezca el horror de Auschwitz. No es una decisión, es la decisión. En esa decisión se juega lo que llamamos humanismo. Es lo que queremos entender por humanismo después de Auschwitz. Preguntamos si es posible un humanismo después de Auschwitz. Es posible que la respuesta sea negativa. Auschwitz es una opción presente en cada decisión que tomamos, en cada gesto que hacemos. Auschwitz es también una posibilidad para la civilización occidental y planetaria. En algunos lugares del planeta así como también en algunos lugares de nuestro espacio cotidiano la opción por Auschwitz ya ha sido tomada. Un humanismo sólo es posible si tenemos a Auschwitz en la mira, como nuestro referente.

Es preciso saberlo: la experiencia, el legado del siglo XX es el legado del horror. Somos herederos de ese legado. Por ello, estamos frente a frente con la experiencia de la muerte de lo humano del hombre en el mundo permanentemente. Es lo que se da en cada esquina de la ciudad. Pero es también lo que se da en la escuela cuando los estudiantes agreden a los profesores o se agreden entre ellos mismos. Es decir, la muerte de lo humano del hombre ha conquistado también los espacios educativos en este Chile de hoy. Lo vemos en la prensa cada día y es también la experiencia de muchos educadores chilenos que se han visto sobrepasados por un sistema inhumano. Lo vemos en las políticas educativas, en las reformas, en la fisonomía que ha ido adoptando la sociedad actual, en su violencia inconmensurable, en el imperio de las estadísticas.

\section{Un niño en Auschwitz.}


Kertész fue un niño en Auschwitz. De un día para otro es arrestado, puesto en un vagón de ferrocarril y enviado a Auschwitz con lo puesto.

Recuerdo que me desperté sobresaltado, probablemente por el sonido agudo de las sirenas que aullaban fuera: la luz débil que entraba por la ventana anunciaba el alba del cuarto día. Me dolía un poco la parte inferior de la columna, a causa de las horas que llevaba en el suelo del vagón. El tren se había detenido, como otras muchas veces, siempre que sonaban las alarmas de combate aéreo. Todos nos agolpábamos detrás de las ventanas como siempre en esos casos, intentando ver algo. Al cabo de un rato, conseguí acercarme a una ventana. No vi nada. El alba era fresca y perfumada, los extensos campos estaban cubiertos por una niebla gris. De repente percibí por detrás de mí, de una manera inesperada, pero aguda y bien definida, como si sonara una trompeta, un fino rayo rojo; comprendí que era el sol que se levantaba. Aquél me pareció un momento magnífico: en casa a estas horas todavía estaría durmiendo. También vi, a mi izquierda, un edificio que anunciaba una estación, pequeña o grande, todavía no podía saberlo, pero una estación ferroviaria. Resultó ser un edificio minúsculo, gris y totalmente desierto, con pequeñas ventanas que estaban cerradas, y aquel techo ridículamente escarpado que había visto el día anterior por aquellos parajes. En la niebla matinal, el edificio iba cobrando una forma cada vez más definida delante de mis ojos, su color se iba transformando de gris a violeta, y las ventanas se iluminaron de repente con los primeros rayos de la luz roja del sol. Otros también vieron el edificio, y yo se lo conté a los que estaban alrededor. Me preguntaron si veía el nombre de alguna localidad. Y sí, lo vi: eran dos palabras que a la luz del sol se distinguían perfectamente; el cartel colgaba del lado más estrecho del edificio, debajo del techo, justo enfrente de nuestro vagón: 'Auschwitz-Birkenau', eso leí, estaba escrito con las típicas letras alemanas, altas y onduladas. Traté en vano de acordarme de mis estudios de geografía, los demás tampoco tenían idea de dónde estábamos. Me senté, pues tenía que ceder el puesto a otro y, como todavía era temprano y tenía sueño, pronto me volví a dormir”. (Kertész, 1975: 79-81).

Para Kertész y sus amigos, el nombre de Auschwitz-Birkenau es toda una sorpresa, un lugar del mapa del que no se tiene noticias, una estación desconocida entre tantas otras igualmente desconocidas. Nada demasiado preocupante. Su protagonista, György, pudo volver a dormirse.

\section{Levi tampoco asocia Auschwitz con ningún lugar conocido.}

Habían cerrado las puertas en seguida pero el tren no se puso en marcha hasta por la tarde. Nos habíamos enterado con alivio de nuestro destino. Auschwitz: un nombre carente de cualquier significado entonces para nosotros pero que tenía que corresponder a un lugar de este mundo. (Levi, 2001: 23). 
La experiencia de la deportación es de por sí traumática. Significa dejar atrás todo cuanto tiene valor en la vida: familia, amigos, trabajo, etcétera. Si a esto le sumamos la poca información sobre el lugar de destino y el sentido mismo del viaje, entonces al dolor hay que agregarle también una importante dosis de angustia e incertidumbre.

A la llegada, lo primero son los gritos, los golpes, la muchedumbre ordenada en filas y al frente de todos un oficial alemán decidiendo la vida o la muerte de cada una de esas personas. Unos a la izquierda, otros a la derecha. ¿La clave de salvación? Decir que se tiene dieciséis años y aparentarlos frente al oficial. Su primera mentira en Auschwitz.

Pero tal vez lo más impactante de todo en ese paisaje surrealista fue la presencia y el aspecto de los prisioneros que salen a recibirlos:

Entonces, en medio de aquella masa humana, vi por primera vez a los hombres que se encontraban allí. Me sorprendió mucho, puesto que era la primera vez en mi vida que veía yo, por lo menos desde tan cerca, unos presos de verdad, con el típico uniforme a rayas de los delincuentes, el gorrito redondo y la cabeza afeitada. Mi primera reacción natural fue retroceder. Algunos de ellos respondían a las preguntas de la gente, otros examinaban el vagón y empezaban a desalojar el equipaje con la experiencia de mozos de carga profesionales y con una rapidez extraña, típica de los zorros. (Kertész, 1975.: 82).

Todavía Kertész, a causa de su temprana edad, no establece la relación correcta. Todavía ve esa otredad semihumana como cosa ajena y extraña, lo que lo hace retroceder. Otra será, en cambio, la experiencia de Primo Levi, quien entró en Auschwitz con veinticuatro años cumplidos y con los ojos más abiertos:

Emergieron, en su lugar, a la luz de los faroles, dos pelotones de extraños individuos. Andaban en formación de tres en tres, con extraño paso embarazado, la cabeza inclinada hacia delante y los brazos rígidos. Llevaban en la cabeza una gorra cómica e iban vestidos con un largo balandrán a rayas que aun de noche y de lejos se adivinaba sucio y desgarrado. Describieron un amplio círculo alrededor de nosotros, sin acercársenos y, en silencio, empezaron a afanarse con nuestros equipajes y a subir y a bajar de los vagones vacíos [...] Nosotros nos mirábamos sin decir palabra. Todo era incomprensible y loco, pero habíamos comprendido algo. Ésta era la metamorfosis que nos esperaba. Mañana mismo seríamos nosotros una cosa así. (Levi, 2001: 28-29)

En esos prisioneros observamos por primera vez de un modo elocuente la muerte del hombre. Esos prisioneros han perdido su condición de personas y Levi piensa que 
terminará convertido en una 'cosa' así. Más adelante, esa será también la experiencia de Kertész. De hecho, la metamorfosis de persona a cosa había comenzado mucho antes del viaje. La segregación y la humillación las habían vivido en sus lugares de origen. En Auschwitz, final del camino, les esperan los malos tratos, el hambre, la enfermedad y la muerte siempre dispuesta a recibirlos.

Primero las duchas, luego el rapado de la cabeza y el cuerpo y finalmente el nuevo vestuario:

A continuación nos encaminamos por un pasillo con dos ventanas iluminadas a la derecha y una pequeña salita sin puerta al final; por cualquier lugar que pasáramos había presos, que distribuían ropa. A mí, como a todos, me dieron una camisa que parecía haber sido azul con rayas blancas y que no tenía cuello -era similar a las que acostumbraban usar nuestros abuelos-, unos calcetines también de la misma época, un par de cordones para los pantalones, un traje de lienzo muy usado, de rayas blancas y azules, igual que el traje de los presos: la mirase como la mirase, aquella ropa era un uniforme de preso. En la pequeña salita abierta pude elegir yo mismo entre los muchos pares de zapatos que había con suela de madera, forrados con tela, y que no tenían cordones sino tres botones a los lados; encontré unos que eran aproximadamente de mi número. También recogí los dos paños de tela gris, que parecían pañuelos más otra prenda imprescindible, el gorro redondo, bastante destrozado, a rayas, también típico de los presos [...] Durante unos instantes estuve indeciso, no sabía exactamente qué hacer, pero no me podía entretener en medio de tantas prisas, tanto jaleo, tanta gente vistiéndose, puesto que tampoco quería quedarme atrás. Me até los pantalones -que eran anchos y no tenían cinturón ni nada parecido - como pude y corriendo; los zapatos eran también muy raros, puesto que la suela era totalmente rígida. Terminé de vestirme y me puse el gorro en la cabeza. Cuando acabé los otros muchachos también estaban ya vestidos, nos miramos atónitos, sin saber si reír o llorar. (Kertész, 1975: 102-103).

Es fuerte esa última expresión: "sin saber si reír o llorar”, pues han experimentado una mutación que los vuelve graciosos, pero a la vez entienden que comienzan a sumergirse en una dimensión infrahumana.

Levi, sometido a los mismos rigores, no deja paso al humor o la ironía:

Al sonar la campana se ha oído despertar al oscuro campo. Inesperadamente el agua ha empezado a caer, hirviendo, de las duchas, cinco minutos de beatitud; pero inmediatamente después irrumpen cuatro tipos (puede que los barberos) que, empapados y humeantes, nos echan a gritos y empellones a la sala contigua, que está helada; aquí, otras personas que gritan nos echan encima no 
sé qué andrajos y nos arrojan a las manos un par de zapatones de suela de madera; sin tiempo para entender lo que pasa nos encontramos ya al aire libre, sobre la nieve azul y helada del amanecer y, descalzos y desnudos, con el ajuar en la mano, tenemos que correr hasta otra barraca, a un centenar de metros. Aquí podemos vestirnos [...] Al terminar, nos quedamos cada uno en nuestro rincón y no nos atrevemos a levantar la mirada hacia los demás. No hay dónde mirarse, pero tenemos delante nuestra imagen, reflejada en cien rostros lívidos, en cien peleles miserables y sórdidos. Ya estamos transformados en los fantasmas que habíamos vislumbrado anoche. (Levi, 2001:38-39).

Gran parte de lo que somos, de esa imagen que tiene cada uno de sí mismo le viene de su vestimenta. Es ella la que nos inserta en el mundo de lo humano, en el mundo social y cultural al que pertenecemos. El vestido no sólo cubre y abriga nuestro cuerpo. También se juega un sentido de lo estético, un rol social y un perfil para nuestra personalidad. Si una vez desnudos nos imponen un traje, que en algunos casos se limita a un puñado de andrajos, nos quitan inmediatamente un aspecto esencial de nuestra identidad humana y nos han transformado en otra cosa.

\section{Lo dirá con toda claridad Levi:}

Entonces por primera vez nos damos cuenta de que nuestra lengua no tiene palabras para expresar esta ofensa, la destrucción de un hombre. En un instante, con intuición casi profética, se nos ha revelado la realidad: hemos llegado al fondo. Más bajo no puede llegarse: una condición humana más miserable no existe, y no puede imaginarse. No tenemos nada nuestro: nos han quitado la ropa, los zapatos, hasta los cabellos; si hablamos no nos escucharán, y si nos escuchasen no nos entenderían. Nos quitarán hasta el nombre: y si queremos conservarlo deberemos encontrar en nosotros la fuerza de obrar de tal manera que, detrás del nombre, algo nuestro, algo de lo que hemos sido, permanezca. (Levi, 2001:39).

Más sensible que Kertész, Levi percibe perfectamente cuál es la naturaleza del campo. Siente la experiencia del despojo no sólo como ausencia de bienes materiales. Siente que su propia dignidad ha sido vulnerada irremisiblemente y que se le ha arrebatado su humanidad. Nótese que el título de su biografía es precisamente Si esto es un hombre. Mientras más profundice en esa degradación gradual, más percibirá que su ser ha sido aniquilado. Nos impresionan sus palabras:

Imaginaos ahora un hombre a quien, además de a sus personas amadas, se le quiten la casa, las costumbres, la ropa, todo, literalmente todo lo que posee: será un hombre vacío, reducido al 
sufrimiento y a la necesidad, falto de dignidad y de juicio, porque a quien lo ha perdido todo fácilmente le sucede perderse a sí mismo; hasta tal punto que se podrá decidir sin remordimiento su vida o su muerte prescindiendo de cualquier sentimiento de afinidad humana; en el caso más afortunado, apoyándose meramente en la valoración de su utilidad. Comprenderéis ahora el doble significado del término "Campo de aniquilación”, y veréis claramente lo que queremos decir con esta frase: yacer en el fondo [...] Häftling: me he enterado de que soy un Häflling. Me llamo 174517; nos han bautizado, llevaremos mientras vivamos esta lacra tatuada en el brazo izquierdo. (Levi, 2001:4041).

Para el caso de Kertész, el Lager le sigue sorprendiendo. Totalmente inocente del lugar a donde ha ido a parar, se asombra, con un dejo de ironía, mientras observa el comportamiento de sus amigos y del personal que lo acompaña en esta tan ridícula estampa:

No puede haber, creo yo, ningún preso que al principio no se extrañe de su condición. También nosotros, los muchachos, estuvimos mirándonos extrañados en el patio al que llegamos después de la ducha. Me fijé en un hombre joven que estaba junto a mí, el cual se examinaba su vestimenta, palpándola de arriba abajo, con mucha atención y dedicación pero también con incredulidad, como si tratara de comprobar la calidad de la tela. Luego miró alrededor como si quisiera decir algo, pero al final no dijo nada porque vio que todos estábamos vestidos igual: por lo menos eso me pareció, aunque quizás estaba equivocado. Incluso con la cabeza rapada, con aquella vestimenta, con su uniforme de preso que le quedaba un poco corto pude reconocerlo por su cara huesuda: era el enamorado que una hora antes -porque una hora antes más o menos había pasado desde nuestra llegada hasta nuestra transformación completa—se había visto obligado a separarse de su enamorada con tanta pena. (Kertész, 1975: 104).

A su corta edad, Kertész intenta sobreponerse al rigor del Lager. Su instinto de supervivencia juega en él un rol importantísimo. No se lamenta al modo de Levi, quien ya ha descubierto la verdad del Campo, sino que intenta sobrevivir cueste lo que cueste. En eso consistía la vida en Auschwitz. También Levi tendrá que adaptarse a esa realidad haciendo lo que sea necesario para mantenerse con vida. Ha hecho una serie de aprendizajes a una velocidad impresionante, movido solamente por la necesidad:

Hemos aprendido bien pronto que los huéspedes del Lager se dividen en tres categorías: los criminales, los políticos y los judíos. Todos van vestidos a rayas, todos son Häftlinge, pero los criminales llevan junto al número, cosido en la chaqueta, un triángulo verde; los políticos un 
triángulo rojo; los judíos, que son la mayoría, llevan la estrella hebraica, roja y amarilla. (...) Y hay otra cosa que hemos aprendido, más o menos rápidamente, según el carácter de cada cual; a responder Jawohl, a no hacer preguntas, a fingir siempre que hemos entendido. Hemos aprendido el valor de los alimentos; ahora también nosotros raspamos diligentemente el fondo de la escudilla después del rancho y nos la ponemos bajo el mentón cuando comemos pan para no desperdiciar las migas. También sabemos ahora que no es lo mismo recibir un cucharón de sopa de la superficie que del fondo del caldero y ya estamos en condiciones de calcular, basándonos en la capacidad de los distintos calderos, cuál es el sitio más conveniente al que aspirar cuando hay que hacer cola [...] Hemos aprendido que todo es útil; el hilo de alambre para atarse los zapatos, los harapos para convertirlos en plantillas para los pies; los papeles, para rellenar (ilegalmente) la chaqueta y protegerse del frío. Hemos aprendido que en cualquier parte pueden robarte, o mejor, que te roban automáticamente en cuanto te falla la atención; y para evitarlo hemos tenido que aprender el arte de dormir con la cabeza sobre un lío hecho con la chaqueta que contiene todo cuanto poseemos, de la escudilla a los zapatos. (Levi, 2001: 50-52).

Aprendizajes que sólo son posibles gracias a la solidaridad de los otros presos, más antiguos, los cuáles le enseñan cómo sobrevivir en este infierno. Por lo mismo, quienes no manejan esa información se exponen a una muerte prematura, lo cual siempre es posible en Auschwitz.

\section{La última lección, Levi nos la cuenta de la siguiente manera:}

Heme aquí, por consiguiente, llegado al fondo. A borrar con una esponja el pasado, el futuro se aprende pronto si os obliga la necesidad. Quince días después del ingreso tengo ya el hambre reglamentaria, un hambre crónica desconocida por los hombres libres, que por la noche nos hace soñar y se instala en todos los miembros de nuestro cuerpo; he aprendido ya a no dejarme robar, y si encuentro una cuchara, una cuerda, un botón del que puedo apropiarme sin peligro de ser castigado me lo meto en el bolsillo y lo considero mío de pleno derecho. Ya me han salido, en el dorso de los pies, las llagas que no se curan. Empujo carretillas, trabajo con la pala, me fatigo con la lluvia, tiemblo ante el viento; ya mi propio cuerpo no es mío: tengo el vientre hinchado y las extremidades rígidas, la cara hinchada por la mañana y hundida por la noche; algunos de nosotros tienen la piel amarilla, otros gris: cuando no nos vemos durante tres o cuatro días nos reconocemos con dificultad. (Levi, 2001: 57-58).

La transformación se ha consumado. El Campo ha mostrado definitivamente su verdad. Un nuevo imperativo se ha apropiado de la mente de los prisioneros, escapar a la muerte, he ahí la única preocupación y para ello todo está permitido. Las condiciones se 
vuelven cada día más apremiantes, el trabajo extenuante, la enfermedad rebelde que comienza en los zapatos y se disemina por todo el cuerpo, el hambre y la sed que vuelven locos a muchos y matan a muchos otros. Los últimos días son inenarrables, pero tanto Levi como Kertész sobreviven al infierno.

Kertész también ha descubierto la verdad, aunque nos la cuenta con su propio estilo:

A pesar de que durante el paseo no entablé conversación con ningún desconocido, tuve ocasión de conocer detalles muy precisos. Allí, enfrente, estaban quemando a nuestros compañeros de viaje, los que habían llegado con nosotros en el mismo tren, todos los que habían pretendido subir a los camiones, todos los que en el examen médico resultaron no aptos para trabajar, por ser demasiado viejos o por cualquier otra razón, todos los niños con sus madres y las futuras madres a las que se le notaba ya el embarazo. Como nosotros, todos ellos desde la estación, habían ido a ducharse. También a todos ellos les habían informado sobre las perchas, los números y la organización de la ducha. Después de pasar por el barbero y recibir el jabón entraron en una sala llena de duchas y de tuberías, pero de los grifos no salía agua sino gas. (Kertész, 1975: 114).

\section{Narración y memoria.}

Kertész y Levi son sobrevivientes. Testimonian de lo que vieron y vivieron, son la voz de aquellos que no volvieron y no pueden por ellos mismos referirnos su testimonio. Levi y Kertész testimonian la ausencia de testimonio de los que no pudieron decir la verdad. Por lo tanto, su verdad es verdad a medias y cuando hablamos de la "verdad" de Auschwitz decimos algo que tampoco hemos conocido y que pronunciamos con la palabra "eso". Pero por la narración podemos pre-sentir el horror. La narración tiene ese efecto maravilloso. Escuchamos a Levi y nos ponemos en su lugar. Entonces no tan sólo sabemos, además sentimos y emocionamos lo que nos dice. Nos muestra ese lugar en donde el hombre ha cedido definitivamente en favor de las circunstancias. Todo este nuevo tipo de aprendizaje no estaba estipulado en la educación tradicional, no fue enseñado en las escuelas y sin embargo en estas circunstancias es el único que cuenta. György, el personaje de Kertész, se lamenta de no haber sabido antes estas cosas.

Pero entonces, según veo ahora, habría tenido que aprender únicamente cosas sobre Auschwitz. Me tendrían que haber explicado todo, con inteligencia, honradez y transparencia. Sin 
embargo, durante los cuatro años de colegio no me habían dicho ni una palabra al respecto. Claro, habría resultado embarazoso y, en realidad, no formaba parte de la cultura general. La desventaja era que tenía que enterarme de todo sobre la marcha, aprender por ejemplo que estábamos en un Konzentrationslager o, lo que es lo mismo, un “campo de concentración”. (Kertész, 1975: 117).

Tampoco hoy nuestra educación sabe enfrentarse con este pasado. Auschwitz no se enseña, Villa Grimaldi tampoco. Se suele pensar que estos Lager constituyen accidentes de la historia, lamentables, pero prescindibles. La educación prefiere formar profesionales, técnicos, científicos y tanto Auschwitz como Villa Grimaldi no contribuyen con esos propósitos. Nuestra cultura cree que podrá sobrevivir y enriquecerse de espaldas a estas masacres. Pareciera que la divisa es olvidar. Pero no para los sobrevivientes. Muchos de ellos vivieron para recordar y hacerles saber al resto del mundo lo que allí había ocurrido. Pero cada vez fueron menos los oídos que recepcionaron el mensaje.

Sin embargo, sabemos que sin memoria no hay futuro digno y humano. Volver sobre estas experiencias que se encuentran en la base de nuestra civilización es una buena manera de impedir que vuelvan a repetirse. Por ello volvemos sobre estas historias que nos cuentan Kertész y Levi. Porque es desde ellas que podemos verdaderamente reconciliarnos con lo humano del hombre. La narración muestra toda su riqueza en estos textos tan valiosos.

Mèlich siente que la sociedad, en su afán de olvidar ese pasado ominoso, se encamina hacia la deshumanización:

Vivimos un tiempo de olvido de la narración. Y este olvido es una muestra más de la negación del otro, de la muerte del otro propia de la modernidad. Y la educación, en el olvido de la palabra narrada, se ha vuelto cada vez más una transmisión de capacidades técnicas y de conocimientos, hasta el punto que ella, la educación, en sí misma, está siendo considerada una tarea técnica. El ser humano, desde esta perspectiva, pierde su humanidad, porque se preocupa exclusivamente por el éxito en el momento presente, y por un futuro en el que cada uno puede ser feliz al margen de los otros. (Mèlich, 2001: 56).

Más adelante, Mèlich vuelve sobre este tema:

La narración es portadora de sentido, no intenta resolver los problemas (al modo de los especialistas técnicos), sino provocar que el ser humano se enfrente a las cuestiones fundamentales 
de su existencia. Por la narración, el ser humano vive el pasado en el presente, comprende que el pasado sigue abierto, que no ha concluido. Por la narración, el ser humano es oyente de las voces excluidas de la historia. Por la narración el lector es hospitalario, es receptivo y responsable del otro. Porque en la narración el lector no lee un informe objetivo, ni siquiera solamente la experiencia del escritor, del superviviente, sino la ausencia del testimonio. A través del relato el lector queda atravesado por un imperativo, el de mantener viva la experiencia del mal radical, de aquellos asesinados en la cámara de gas del Lager. (Mèlich, 2001: 56-57).

Este es, pues, un ejercicio de memoria histórica y política y es también un ejercicio de filosofía ética y pedagógica. Porque a través del relato sabemos de esa experiencia de despojo de humanidad. Gracias a ese pensar-recordando, dejándose aleccionar como dirá Mèlich, no sólo empatizamos con el dolor y el sufrimiento de tantos, sino que también obtenemos un aprendizaje muy significativo: descubrimos que sólo Auschwitz puede elevarnos a nivel de humanidad, recordando el gesto inhumano tan frecuente en el campo, pero también el gesto humano, escaso pero infinitamente significativo:

Además, está claro que para la construcción de una filosofía de la educación, esta figura es central, porque en ella vemos la esperanza en la humanidad. Si tiene algún sentido la educación, es fundamentalmente porque existen personas que hacen el bien, porque existen benefactores $o$ bienhechores. La verdad, nadie sabe mejor que el prisionero lo que ese gesto significa y el valor que entraña, y por lo mismo sólo él sabe que puede estremecer la existencia entera. Tiene ese gesto una elocuencia que es muy difícil traducir en palabras, pero ostenta tal densidad ontológica, que no tenemos más remedio que llamarle «bien» $\mathrm{o}$ «bien absoluto», o como decimos, reconocimiento de lo humano del hombre en el mundo, afectando también, de este modo, a la totalidad de su dimensión simbólica. Ese gesto nos aleja decididamente de Auschwitz, nos pone en dirección a un futuro posible para la humanidad, no es que todo sea campo (Lager), pero sabemos que hay un gesto a lo menos que nos aleja de él. Como educadores es urgente que conozcamos la naturaleza de ese gesto, pues con nuestros pequeños gestos podríamos darle eternidad. Eso es la esperanza. (Montes, 2014: 90).

Conocer los alcances de ese gesto humano implica también saber hasta dónde somos capaces de efectuar nosotros ese gesto abriendo una puerta a la esperanza.

Tenemos, por lo tanto, dos lecciones de Auschwitz, que expresa adecuadamente Bauman: 
La lección del Holocausto es la facilidad con que la mayor parte de las personas, cuando se las pone en una situación en la que no tienen una elección buena o bien esa elección es demasiado costosa, se convencen a sí mismos y se alejan de la cuestión del deber moral (o no se convencen de seguirla) adoptando, por el contrario, los preceptos del interés racional y la propia conservación. En un sistema en el que la racionalidad y la ética apuntan en direcciones opuestas, la humanidad es la principal derrotada. El mal puede hacer su trabajo sucio con la esperanza de que la mayor parte de las personas, durante la mayor parte del tiempo, se abstengan de hacer cosas imprudentes y precipitadas, y resistirse al mal es imprudente y precipitado. El mal no necesita de seguidores entusiastas ni de un público que le aplauda. El instinto de conservación lo hará todo, animado por el pensamiento reconfortante de que, gracias a Dios, todavía no me toca a mí: si ahora me escondo, todavía me puedo escapar [...] Y hay otra lección del Holocausto que no es menos importante. Si la primera lección contenía una advertencia, la segunda nos ofrece una esperanza. Es la segunda lección la que hace que merezca la pena insistir en la primera [...] La segunda lección nos dice que poner la propia conservación por encima del deber moral no es algo en absoluto predeterminado, inevitable e ineludible. A uno lo pueden presionar para que lo haga, pero no le pueden forzar a hacerlo $\mathrm{y}$, en consecuencia, no puede traspasar la responsabilidad moral de haberlo hecho a los que ejercieron la presión. No importa cuántos eligieron el deber moral por encima de la racionalidad de la propia conservación. Lo que importa es que algunos lo hicieron. El mal no es todopoderoso. Se puede resistir. El testimonio de los pocos que se le resistieron acaba con la autoridad de la lógica de la propia conservación. Demuestra lo que en definitiva es: una elección. Uno se pregunta cuánta gente debe desafiar a esa lógica para que el mal quede incapacitado. ¿Existe un umbral mágico de oposición más allá del cual la tecnología del mal se detenga con un gran ruido de frenos? (Bauman, 1997: 268-269).

De ese bien esperanzador escribimos en nuestro artículo antes citado. Pensamos que un humanismo pasa por hacerse cargo de esos gestos en la vida, pero de eso hablaremos más adelante.

\section{Humanismo y educación.}

Por la dimensión simbólica de Auschwitz, éste ya no tiene que ser necesariamente el campo de concentración y exterminio nazi. Ahora se expande a la vida humana toda, transformándose en su referente ético. Hay dos gestos primordiales como lo apuntó con toda claridad Martin Buber: el gesto 'yo-tú' y el gesto 'yo-ello'. Por el gesto 'yo-ello' cosifico a los demás y me cosifico a mí mismo en cuanto lo aplico a las realidades humanas. El gesto 'yo-ello', puesto en dirección al hombre, nos conduce directamente a 
Auschwitz. Constituye el imperio de los instintos y la autoreferencia del yo. El gesto 'yoello’ conduce al ‘sálvense quien pueda'. Buber (1998: 11) lo expresa del siguiente modo al principio de su célebre obra:

Para el ser humano el mundo es doble, según su propia doble actitud ante él. La actitud del ser humano es doble según la duplicidad de las palabras básicas que él puede pronunciar. Las palabras básicas no son palabras aisladas, sino pares de palabras. Una palabra básica es el par Yo-Tú. La otra palabra básica es el par Yo-Ello, donde, sin cambiar la palabra básica, en lugar de Ello pueden entrar también las palabras Él o Ella. Por eso también el Yo del ser humano es doble. Pues el Yo de la palabra básica Yo-Tú es distinto del de la palabra básica Yo-Ello.

Para nosotros, la tarea es reivindicar el valor y sentido de la existencia humana en tanto que humana. Es lo humano de la humanidad lo que nos interesa. Auschwitz es el paradigma de la relación Yo-Ello, siguiendo con el lenguaje buberiano. La persona en cuanto cruza su umbral es inmediatamente reducida a la condición de número mediante un tatuaje como lo señala Levi y de cosa de la que nos habló también Levi en las citas anteriores. Es la razón instrumental en marcha, sin límites ni cortapisas. Razón instrumental que sigue obrando impunemente en la sociedad actual. La objetivación del mundo está hoy de moda. Horkheimer observa todo esto con preocupación:

Las esperanzas de la humanidad parecen hoy mucho más alejadas de su cumplimiento de lo que pudieran estarlo incluso en las épocas de tanteos inseguros en los que fueron formuladas por vez primera por los humanistas. Incluso a pesar de la ampliación del horizonte del pensamiento y de la acción a efectos del saber técnico, la autonomía del individuo, su capacidad para ofrecer resistencia al aparato creciente de la manipulación de las masas, la fuerza de la fantasía, su juicio independiente, parecen retroceder claramente [...] Los avances en el ámbito de los medios técnicos se ven acompañados de un proceso de deshumanización. El progreso amenaza con destruir el objetivo que estaba llamado a realizar: la idea del hombre. (Horkheimer, 2002: 43-44).

Y este proceso afecta decididamente la educación, o mejor dicho, esa educación del hombre y para el hombre, lo que llamamos desde siempre: humanismo.

Necesitamos ejemplos en un mundo sin ejemplos. El siglo XX nos ha legado la experiencia del mal en estado puro. Los campos de exterminio, la bomba atómica, las guerras interminables y un largo etcétera que impone una visión de dominio sobre todo el 
planeta y sobre toda la humanidad. Y ese gesto de dominio, en tanto no se vincula creativamente con la totalidad, termina por destruirla.

Mèlich nos habla del nuevo totalitarismo que impone la ciencia y la técnica sobre todas las cosas: el secreto deseo de posesión y dominio sobre lo real, el Yo-Ello de Buber.

Estoy convencido de que hay en la cultura occidental un deseo de dominarlo todo, de explicarlo todo, de poseerlo todo, de reducir todo lo extraño a lo propio, de apropiarse de lo que no tiene sentido conceptual para darle un sentido conceptual. (Mèlich, 2004:57).

Pero es preciso volver sobre la lección de Auchwitz. La lección de Auschwitz será volver a instaurar como gesto vital la palabra 'Yo-Tú'. Y, siguiendo con esta figura, tendríamos también que agregar el componente comunitario del 'otro hombre' (Yo-Tú-Él), como lo expresa la filósofa argentina, Dina Picotti:

La tercera persona implica la relación más lejana del yo-él o tú-él, imprescindible para la constitución plena del nosotros de la comunidad; sin ella ésta propiamente no existe. Nuestra historia registra, además, una experiencia dolorosa y por ello mismo imborrable, en cuanto la tercera persona fue también el des-conocido, el marginado y en los últimos tiempos el desaparecido y el olvidado o desapercibido en el anonimato. A través de esta experiencia inocultable se advierte mejor cómo cuando se ignora o elimina la tercera persona y se reduce la comunidad al sector más interesado del yo-tú, no sólo se la mutila sino que se le impide realmente ser, en cuanto no se la reconoce en toda su realidad positiva y negativa, en toda su identidad histórica, fuente de sus posibilidades auténticas (Picotti, 1990: 18).

Auschwitz nos enseña que somos comunidad, que el nuevo pensamiento se construye esencialmente desde el 'Él' que espera, a través de nosotros, decir su propia voz y obtener justicia. Nuestra perfección moral pasa por reconocer que el otro hombre constituye el centro de nuestra responsabilidad.

Hay un 'otro' hombre que es también un niño, un pequeño niño en las barracas de Auschwitz. El gesto pedagógico por excelencia se expresa en esta anécdota de Levi:

Hurbinek no era nadie, un hijo de la muerte, un hijo de Auschwitz. Parecía tener unos tres años, nadie sabía nada de él, no sabía hablar y no tenía nombre: aquel curioso nombre de Hurbinek se lo habíamos dado nosotros, puede que hubiera sido una de las mujeres que había interpretado con aquellas sílabas algunos de los sonidos inarticulados que el pequeño emitía de vez en cuando. Estaba paralítico de medio cuerpo y tenía las piernas atrofiadas, delgadas como hilos; pero los ojos, perdidos 
en la cara triangular y hundida, asaeteaban atrozmente a los vivos, llenos de preguntas, de afirmaciones, del deseo de desencadenarse, de romper la tumba de su mutismo. La palabra que le faltaba y que nadie se había preocupado de enseñarle, la necesidad de la palabra, apremiaba desde su mirada con una urgencia explosiva: era una mirada salvaje y humana a la vez, una mirada madura que nos juzgaba y que ninguno de nosotros se atrevía a afrontar, de tan cargada como estaba de fuerza y dolor. (Levi, 2002: 30-31).

¿Qué hace Hurbinek en Auschwitz? Una pregunta sin respuesta para todos quienes observan atónitos al pequeño, erguido en la mitad de la barraca, como si estuvieran presenciando un fantasma. Nadie sabe a qué atinar. "Los niños, en Birkenau, eran aves de paso: después de unos días se los transfería al Block de los experimentos, o directamente a la cámara de gas", nos dice Levi (Levi, 2002: 35).

Pero hay un pequeño adolescente que hace un gesto esencial. Se llama Henek, o al menos ese es el nombre con el que se le conoce en el Lager. Henek decidió cuidar de Hurbinek. Hizo el gesto ético y pedagógico esencial:

Henek se pasaba junto a la cuna de Hurbinek la mitad del día. Era maternal más que paternal: es bastante probable que, si aquella convivencia precaria que teníamos hubiese durado más de un mes, Henek hubiese enseñado a hablar a Hurbinek; seguro que mejor que las muchachas polacas, demasiado tiernas y demasiado vanas, que lo mareaban con caricias y besos pero que rehuían su intimidad [...] Henek, tranquilo y testarudo, se sentaba junto a la pequeña esfinge, inmune al triste poder que emanaba; le llevaba de comer, le arreglaba las mantas, lo limpiaba con hábiles manos que no sentían repugnancia; y le hablaba, naturalmente en húngaro, con voz lenta y paciente. Una semana más tarde, Henek anunció con seriedad, pero sin sombra de presunción, que Hurbinek había dicho una palabra. ¿Qué palabra? No lo sabía, una palabra difícil, que no era húngara: algo parecido a massklo, matisklo. En la noche aguzamos el oído: era verdad, desde el rincón de Hurbinek nos llegaba de vez en cuando un sonido, una palabra. No siempre era exactamente igual, en realidad, pero era una palabra articulada con toda seguridad; o, mejor dicho, palabras articuladas ligeramente diferentes entre sí, variaciones experimentales en torno a un tema, a una raíz, tal vez a un nombre [...] Hurbinek siguió con sus experimentos obstinados mientras tuvo vida. En los días siguientes todos los escuchamos en silencio, ansiosos por comprenderlo, entre nosotros había gente que hablaba todas las lenguas de Europa: pero la palabra de Hurbinek se quedó en el secreto. No, no era un mensaje, no era una revelación: puede que fuese su nombre, si alguna vez le había tocado uno en suerte; puede (según nuestras hipótesis) que quisiese decir 'comer', o 'pan'; o tal vez 'carne' en bohemio, como sostenía con buenos argumentos uno de nosotros que conocía esa lengua [...] 
Hurbinek, que tenía tres años y probablemente había nacido en Auschwitz, y nunca había visto un árbol; Hurbinek, que había luchado como un hombre, hasta el último suspiro, por conquistar su entrada en el mundo de los hombres, del cual un poder bestial lo había exiliado; Hurbinek murió en los primeros días de marzo de 1945, libre pero no redimido. Nada queda de él: el testimonio de su existencia son estas palabras mías. (Levi, 2002: 31-33).

Henek encarna exactamente el gesto ético y pedagógico por excelencia. Ese gesto, a fuerza de insólito, ocurre dentro de una barraca de Auschwitz, de lo que inferimos que Auschwitz también es ese gesto. Levi en otro momento nos habla de Lorenzo, quien le salvó la vida dentro del campo. Hay gestos sorprendentes que nos emocionan por su honestidad y valentía. Porque un gesto bueno tiene su precio en Auschwitz.

Hablamos de un gesto ético, porque se ciñe a un principio universal: el cuidado por el otro hombre, sobre todo por el que sufre y que en su silencio clama por justicia. Hay un reconocimiento de un valor inmenso y se dispone a realizarlo en un gesto libre y sereno.

Henek es la expresión de la ética. Henek es el que entiende que la humanidad, lo humano, no se da necesariamente en el diálogo recíproco entre iguales, en el pacto, o en la negociación. Henek comprende que la humanidad no es, en este caso, el logos, o el deber categórico de la razón pura práctica. Henek se limita simplemente a acoger a Hurbinek, a sentarse junto a él, a arreglarle las mantas, a limpiarle y a hablarle con voz lenta y paciente. Henek es más maternal que paternal, porque acaricia a Hurbinek, le mima, le cuida. En Henek encontramos la ética no como cuidado de sí, sino como cuidado del otro, de ese otro que es Hurbinek. (Mèlich, 2001: 40).

También hablamos de un gesto pedagógico, un gesto de acogida. Es un gesto humano, porque es un gesto compasivo. Y es un gesto pedagógico porque se mueve entre valores y tiene carácter ejemplarizante. Decíamos que el siglo XX nos había legado una cultura del horror de la cual somos legítimos herederos. Eso significa que en nuestros gestos se sigue reproduciendo de mil formas distintas, consciente o inconscientemente, los gestos que hicieron posible Auschwitz. Frente a los problemas que enfrenta la sociedad chilena en materia de educación, salud, seguridad, etc., escuchamos las viejas voces que promueven soluciones violentas y radicales. Una sociedad enferma que vuelve a sentir nostalgias por el dictador, porque no conoce otras salidas. No sabe de encuentros, de diálogos, de cuidado del otro, porque no tiene referentes. Los egoísmos, los individualismos campean en una sociedad que se pretende exitosa a pesar de las 
estadísticas. Auschwitz nos enseña que frente a la violencia, siempre es posible el gesto transformador. La educación no es otra cosa que ese gesto transformador por el cual, se deja en libertad el ser del educando y se lo promueve hacia cotas más altas de humanidad. Educar es en el fondo, formar moralmente a las personas, enseñarles que el ser sólo es alcanzable desde la responsabilidad del gesto bueno.

Cuando hablamos de la dimensión simbólica de Auschwitz, hablamos del gesto cotidiano, en la escuela, en el trabajo, en la calle. Es el gesto que procede a un preguntarse previo: ¿Estoy verdaderamente haciendo retroceder Auschwitz con este gesto o estoy haciéndolo posible aquí y ahora? Se trata de un gesto pedagógico, porque piensa en valores, realiza valores. Descubre que la libertad o es libertad responsable o no es libertad. Libertad para el consumo no es libertad. Pero lo que se promueve en los medios es libertad para el consumo. Lo que se promueve en la escuela es el exitismo. No se habla de valores. Pero enseñar es otra cosa. Enseñar después de Auschwitz es enseñar los valores que nos comprometen con los otros, sobre todo con aquellos que necesitan de nosotros como Hurbinek necesita de Hernek.

El nuevo humanismo necesita de gestos humanos. Gestos concretos, actos que reivindiquen precisamente el valor de lo humano. Asumimos desde ya que lo inhumano no es parte de lo humano, por mucho que se pueda entender así en estos tiempos tan relajados. Para nosotros lo humano son valores humanos: los viejos valores de la solidaridad, de la compasión, de la verdad. Cada uno de esos valores aleja a Auschwitz de nuestro futuro, y no hay otro fin más relevante de la educación que ese:

La exigencia de que Auschwitz no se repita es la primera de todas las que hay que plantear a la educación. Precede tan absolutamente a cualquier otra que no creo deber ni tener que fundamentarla. No puedo comprender por qué se le ha dedicado tan poca atención hasta el momento. Ante la monstruosidad de lo ocurrido, fundamentarla tendría algo de monstruoso. Que se haya tomado tan escasa consciencia de esta exigencia, y de los interrogantes y cuestiones que van con ella de la mano, muestra, no obstante, que lo monstruoso no ha calado lo bastante en las personas. Lo que no deja de ser un síntoma de la pervivencia de la posibilidad de repetición de lo ocurrido si depende del estado de consciencia y de inconsciencia de las personas. Cualquier posible debate sobre ideales educativos resulta vano e indiferente en comparación con esto: que Auschwitz no se repita. (Adorno, 1998: 79). 
Tener a Auschwitz en la mira es no olvidar nunca que estamos al borde de una recaída en lo inhumano, probablemente sin saberlo. Debemos pensar dos veces antes de actuar. Recordar el gesto bueno de Auschwitz y el gesto malo de Auschwitz. Luego, debemos recuperar la serenidad y hacer lo que nos parece correcto. Podemos equivocarnos. Pero aprendemos. La educación es una cuestión de vida, pero de vida comprometida.

\section{Referencias bibliográficas}

Adorno, Th. (1998). Educación para la emancipación. Madrid: Ediciones Morata.

Bauman, Z. (1998). Modernidad y Holocausto. Toledo: Sequitur.

Buber, M. (1998). Yo y tú. Madrid: Caparrós Editores.

Horkheimer, M. (2002). Crítica de la razón instrumental. Madrid: Editorial Trotta.

Kertész, I. (2006). Sin destino. Barcelona: Acantilado.

Levi, P. (2001). Si esto es un hombre. Barcelona: Muchnik Editores.

Levi, P. (2002a). La tregua. Barcelona: Muchnik Editores.

Levi, P. (2002b). Los hundidos y los salvados. Barcelona: Muchnik Editores.

Mèlich, J-C. (2001). La ausencia del testimonio. Ética y pedagogía en los relatos del Holocausto. Barcelona: Anthropos Editorial.

Mèlich, J.C. (2004). La lección de Auschwitz. Barcelona: Editorial Herder.

Montes, J. (2014). La figura del benefactor: el bien como gesto pedagógico. Temas de Educación, 20, 2, 77-94.

Picotti, D. (1990). El descubrimiento de América y la otredad de las culturas. Buenos Aires: RundiNuskin Editor.

Reyes, M. (2003). Memoria de Auschwitz. Actualidad moral y política. Madrid: Editorial Trotta. 